\title{
ARAŞTIRMA/RESEARCH
}

\section{İntrakranial anevrizma cerrahisi sonuçları: tek merkez deneyimi}

\author{
Outcome of intracranial aneurysm surgery: single center experience
}

\author{
Murat Ulutaş
}

Sanko Üniversitesi Tip Fakültesi, Konukoğlu Hastanesi Nöroşirurji Bilim Dalı, Gaziantep/Turkey

$$
\text { Cukurova Medical Journal 2016;41(4):732-743. }
$$

\section{Abstract}

Purpose: Intracranial aneurysms are the most common reason of the subarachnoid hemorrhages and cause significant rate of morbidity and mortality. In this article, we aimed to share the results of our intracranial aneurysm surgery.

Material and Methods: The results have been obtained by scanning the data of the patients who operated or treated by the reason of $\mathrm{SAH}$ and intracranial aneurysm, in our hospital between the years 2003 and 2015.

Results: The 344 subarachnoid hemorrhage cases admitted to Sanko University Konukoglu Hospital and 313 intracranial aneurysms were identified on $270(78.5 \%)$ cases and 311 aneurysms were surgically clipped. There were single aneurysm on $232(85.9 \%)$ and multiple aneurysms on $38(14.1 \%)$ cases. Clinically vasospasm occurred in $19.6 \%$ of cases. There was a strong correlation between Hunt and Hess grade on admission and vasospasm development. The mortality of single and multiple aneurysm were $12.5 \%$ and $26.5 \%$ respectively. The overall mortality and morbidity rates were $14.4 \%$ and $21.5 \%$ respectively .

Conclusion: Multiple aneurysms, poor grade and intracerebral hematomas are poor prognostic factors. The patients who have subarachnoid hemorrhage should be monitored by an experienced team of neurosurgery and intensive care and should be operated on as soon as possible because of rehemorrhage risk. The surgical clipping as a gold standard is still an affective and successful method.

Key words: Subarachnoid hemorrhage, intracranial aneurysm, microsurgery, vasospasm

\section{GİRİŞ}

İntrakranial anevrizmalar, travma dişında en fazla subaraknoid kanamaya (SAK) neden olan intrakranial patolojidir ve siklı̆̆1 y1llık 6-8/100 000
$\ddot{\mathrm{O}} \mathrm{z}$

Amaç: İntrakranial anevrizmalar travma dıșında en sık subaraknoid kanamaya neden olan patolojidir ve önemli morbidite ve mortaliteye neden olmaktadır. Bu makale ile tek merkezde yapılan anevrizma cerrahisi sonuçlarımızı paylașmak amaçlanmıștır.

Gereç ve Yöntem: 2003-2015 yılları arasında Sanko Universitesi Konukoğlu hastanesinde tedavi edilen subaraknoid kanama ve intrakranial anevrizma nedeniyle opere edilen olgularının bilgileri taranarak sonuçlar elde edilmiştir

Bulgular: Kliniğimize başvuran 344 subaraknoid kanama olgusunun 270 (\%78.5)'inde toplam 313 intrakranial anevrizma tespit edildi ve toplam 311 anevrizma cerrahi olarak kliplendi. Tek anevrizmalı 232 (\%85.9), multipl anevrizmalı 38 (\%14.1) olgu saptandı. Başvuru Hunt ve Hess evre ile vazospazm gelişmesi arasında anlamlı ilişki olduğu saptandı. Olguların \%19.6'sinde klinik vazospazm geliști ve genel mortalite $\% 14.4$, morbidite $\% 21.5$ oranında idi.

Sonuç: Çoklu anevrizma ve intraserebral hematom varlı̆̆1 ile yüksek Hunt ve Hess evre ile başvuru, sonucu etkileyen en önemli faktörlerdir. Bu olgular tecrübeli nöroşirurji ve yoğun bakım ekibi ile takip edilmeli, tekrar kanama riski nedeni ile mümkün olan en kısa sürede opere edilmelidir. Altın standart olarak yerini koruyan cerrahi klipleme tedavide halen etkili ve başarılı bir yöntemdir.

Anahtar kelimeler: subaraknoid kanama, intrakranial anevrizma, miikrocerrahi, vazospazm

olduğu bildirilmiştir ${ }^{1}$. Tedavi edilmeyen bu hastaların yaklaşık \%15-20'sinde ilk iki haftada tekrar kanama oluştuğu, ilk 30 günde $\% 45$ oranında ölüm ile sonuçlandığ1 bildirilmiştir ${ }^{2,3}$. SAK hastalarının \%30'u orta ve şiddetli sakatllk, yaklaşık \%66'sında 
ise başarılı cerrahi ve tedaviye rağmen kanama öncesi yaşam kalitesine dönememektedir ${ }^{4,5}$. Subaraknoid kanamanın klinik ve radyolojik bulgularını değerlendirmek için çeşitli evreleme sistemleri vardır. Bunların içinde klinik değerlendirme için sıklıkla Hunt\&Hess $(\mathrm{H} \& \mathrm{H})$, radyolojik değerlendirme için Fisher evreleme sistemleri kullanılmaktadır ${ }^{6,7}$. Yüksek evreli olguların kötü prognaza sahip olduğu bildirilmiştir.

Dandy tarafindan 1938 yilında ilk anevrizma klipleme gerçekleştirildikten sonra nöroanestezinin gelişmesi, mikroşirurjikal alet ve operasyon mikroskobunun katkıları ile günümüzde serebral anevrizma cerrahisinde bașarılı sonuçların alınmasını sağlamıștır ${ }^{8-11}$. Intrakranial anevrizmalarun cerrahi tedavisine alternatif olarak 1990 yllında Gugliemi tarafindan endovasküler girişim ile anevrizma içinin koil ile doldurma tedavisi geliştirilmiştir ${ }^{12}$. Ancak cerrahi klipleme halen yaygın ve güvenilir yöntem olarak kullanılmaya devam etmektedir.

Bu çalışmada tek merkezde yazar tarafindan takip ve tedavisi yapilan SAK ve intrakranial anevrizma nedeni ile ameliyatı yapılan olguların başvuru sırasındaki klinik ve radyolojik evreleri ile sonuç arasındaki ilişkisi, anevrizmaların anatomik lokalizasyonları, cerrahi sırasında-sonrasında oluşan komplikasyon, vazospazm ve sonuçlarının literatür eşliğinde tartışılması hedeflenmiştir.

\section{GEREÇ VE YÖNTEM}

Konukoğlu Hastanesi; 600 klinik, 34 cerrahi yoğun bakım ünitesi yatağ1 ve 10 ameliyat odas1 ile tüm branşlarda hizmet vermekte olup 2013'den itibaren Sanko Üniversitesi Tip Fakültesinin hastanesi olarak hasta kabul etmektedir. Teşhise yönelik olarak 3 tesla magnetik rezonans görüntüleme (MRI), 2x64 kesitli bilgisayarlı tomografi (BT) ve digital subtraction angiografi (DSA) ile tetkik yapılabilmektedir. Nöroşirurji ameliyathanesinde bulunan 2 adet yüksek hızlı drill, cerrahi mikroskop (Leica M525), ultrasonik aspiratör ve mikrocerrahi aletleri ile vasküler, tümör, spinal ve travma ameliyatları yapılabilmektedir. Olguların klinik bilgileri, radyolojik ve laboratuvar tetkikleri dosyalama ve digital ortamda depolanmaktadır.

\section{Subaraknoid Kanama Olgularının Yönetimi}

Klinik bulgu ve nörolojik değerlendirme sonrası SAK teşhisi, BT ve/veya lomber ponksiyon ile konulduktan sonra yoğun bakım ünitesinde analjezi, antiödem (deksametazon) ve parenteral sıvı desteği başlanarak Glasgow Koma Skala ile olguların takiplerine başlandi. Epileptik nöbet riski olan (geçirilmiş nöbet, kortikal hematom gibi) olgulara antiepileptik başland. Başvuru $H \& H$ ve Fisher evreleri not edildi. Öncelikte BT angiografi, gerektiğinde DSA ile ileri tetkik yapıldıktan sonra anevrizma saptanan olgulara tedavi seçenekleri (endovasküler girişim veya cerrahi klipleme) hakkında bilgi verildikten sonra ameliyata alındı. Ameliyat sonrası yoğun bakım ünitesinde antiödem ve Hipertansiyon, Hipervolemi, Hemodilusyon $(\mathrm{HHH})$ tedavisi ile takibe devam edildi. Olgular, özellikle hiperglisemi ve yüksek ateşten korunmaya çalışıldı. Ameliyat sonrası, olguların sistolik arteryel tansiyonu $140 \mathrm{mmHg}$ altına düşürülmemeye çalışıldı, ve gerektiğinde dopamin infüzyonu bașlandi. Hemodilusyon için mannitol, hipervolemi için ise taze donmuş plazma verildi, santral venöz basınc1 8 $\mathrm{mmHg}$ düzeyinde tutulmaya çalışıldı. Aldığı çıkardığı ile sıv1 dengesi kan elektrolit takibi yapıldı. Cerrahi komplikasyon ve ameliyat sonrası kontrol için kontrol kranial BT çekildi. Vazospazm gelişme riski yüksek veya vazospazm bulguları olan olguların yoğun bakım takiplerine devam edildi. $\mathrm{HHH}$, antiödem ve gerektiğinde derin sedasyon ve analjezi ile entübe edilerek respiratöre bağlanarak hiperventilasyon arteriyel karbondioksit 27-30 $\mathrm{mmHg}$, oksijen $100 \mathrm{mmHg}$ ) uyguland.

Çalışmamızda, 2003-2015 yılları arasında Sanko Üniversitesi Konukoğlu Hastanesi Nöroşirurji bölümünde yazar tarafindan takip ve tedavisi yapılan SAK olguları incelenmesi için etik kurul onayı alındı. Y1llik ortalama 20-25 intrakranial anevrizma ameliyat edilmekte ve özellikle bahar aylarında SAK başvurusunda yoğunlaşma olmaktadır. Olguların bilgilerine, hastanenin bilgi işlem taraması ile elde edilen dosya, epikriz ve ameliyat notlarından ulașıldı. Olguların yaş, cinsiyet, başvuru H\&H evre (Evre 1: Asemptomatik, hafif başağrisı ve ense sertliği, Evre 2: Orta-şiddetli başağrısı, ense sertliği, kranial sinir felci olabilir ama taraf bulgusu yok, Evre 3: Şuur somnolans ve hafif fokal nörolojik defisit mevcut, Evre 4: Şuur stupor, orta-şiddetli hemiparezi mevcut, Evre 5: Koma ve deserebre postür mevcut $)^{7}$, Fisher evrelemesine göre BT bulgular1 (Evre 1: Kan yok, Evre 2: Diffuz subaraknoid kanın $<1 \mathrm{~mm}$ vertikal kalınlığı, Evre 3: Lokalize pihtı veya subaraknoid kanın $>1 \mathrm{~mm}$ vertikal kalınlı̆̆ı, Evre 4: Intraserebral veya intraventriküler hematom varlığı. Diffuz SAK eşlik edebilir veya SAK olmayabilir) ${ }^{6}$, 
Genişletilmiş Glasgow Outcome Skala (GGOS) ${ }^{13}$ skorları, SAK'a neden olan anevrizmaların anatomik lokalizasyonları, cerrahi sırasında ve sonrasında oluşan komplikasyon ve sonuçları incelendi.

\section{İstatistiksel analiz}

İstatistiksel analizler için SPSS yazılımı (Statistical Package for Social Science, version 22.0 Inc, Chicago, ABD) kullanıldı. H\&H grade, Fisher grade ve GGOS arasındaki ilişkiyi saptamak için Pearson korelasyon analizi kullanıldı. Karşılaştırma için ise Ki-kare testi uygulandi. p değeri 0.05 'den küçük olanlar istatistiksel olarak anlamlı olarak düşünüldü.

\section{BULGULAR}

Toplam 344 olgu SAK ve/veya intraserebral hematom (Fisher grade IV) nedeni ile tedavi edildi. Anevrizma saptanmayan veya opere edilemeyen 74
(\%21.5) olgu vardı. Bunların 28 (\%37.8)'i prepontin ve perimezensefalik SAK (PMSAK) idi. Bu olgulara BT angiografi yapıldı ve vasküler patoloji saptanmadi. PMSAK olgularının hepsinin nörolojik muayeneleri normaldi ve yapilan tetkik ve tedavileri sonras1 taburcu edildi. 19 (\%25.7) olguda sisternal SAK mevcuttu ancak BT angiografi ve 1 ay sonraki DSA tetkiklerinde anevrizma saptanmad1, bu olgulardan bir tanesi kaybedildi. H\&H grade 5 ve pupiller fix dilate olan $25(\% 33.8)$ olguya ileri tetkik yapılmadan yoğun bakım ünitesinde medikal tedavi ile takip edildi ancak hepsi ölümle sonuçland. Bu olgularin 9 tanesi kardiak arrest ve yeniden canlandirma sonrası hastanemize getirilmişti. 2 olgumuzda ise ameliyat öncesi hazırlık döneminde tekrar kanama oluştu ve ameliyat yapılamadan kaybedildi. Toplam 344 SAK olgusunda erken dönemde kardiak arrest gelişme oranı \%2.6, tekrar kanama oranı \%0.6 olarak belirlendi (Tablo 1).

Tablo 1. Anevrizma saptanamayan veya opere edilemeyen SAK olgularının dağılımı ve ölüm oranları

\begin{tabular}{|l|c|c|c|c|}
\hline & PMSAK & $\begin{array}{c}\text { H\&H evre 5 ve fix } \\
\text { dilate pupil }\end{array}$ & $\begin{array}{c}\text { Angiografi } \\
\text { normal SAK }\end{array}$ & Tekrar kanama \\
\hline Cinsiyet (K/E) & $18 / 10$ & $9 / 16$ & $7 / 9$ & $2 / 0$ \\
\hline Yaş (Yil) & $\begin{array}{c}48 \pm 9.2(35- \\
68)\end{array}$ & $59 \pm 8.3(44-84)$ & $51 \pm 10.1(44-79)$ & $41(39$ ve 43) \\
\hline Hasta sayısı (n:74) & $28(\% 37.8)$ & $25(\% 33.8)$ & $19(\% 25.7)$ & $2(\% 2.7)$ \\
\hline Ölüm & 0 & $25(\% 100)$ & $1(\% 5.2)$ & $2(\% 100)$ \\
\hline $\begin{array}{l}\text { Toplam hasta sayısına } \\
\text { göre ölüm (n:344) }\end{array}$ & 0 & $\% 07.3$ & $\% 0.3$ & $\% 0.6$ \\
\hline
\end{tabular}

PMSAK: Perimezansefalik subaraknoid kanama

Tablo 2. Anevrizma nedeni ile opere edilen olguların yaş, cinsiyet ve $\mathrm{H} \& H$ evre'sine göre dağılımı

\begin{tabular}{|l|c|c|c|}
\hline & Kadın (n:160) & Erkek (n:110) & Toplam \\
\hline Yaş (y1) & $55.1 \pm 14.6(12-79)$ & $51.3 \pm 11.15(18-77)$ & $53.5 \pm 12.2(12-79)$ \\
\hline H\&H Evre 1 & $31(\% 68.8)$ & $14(\% 31.2)$ & $45(\% 16.7)$ \\
\hline H\&H Evre 2 & $54(\% 69.2)$ & $24(\% 30.8)$ & $78(\% 28.9)$ \\
\hline H\&H Evre 3 & $57(\% 59.3)$ & $39(40.7)$ & $96(\% 35.5)$ \\
\hline H\&H Evre 4 ve 5 & $18(\% 35.3)$ & $33(\% 64.7)$ & $51(\% 18.9)$ \\
\hline
\end{tabular}

Bulguların istatistiksel incelemesinde başvuru H\&H evre ile cinsiyet arasında anlamlı farklılık saptandı ( $\mathrm{p}<0.05)$. Bu farklılığın evre 4 ve 5 ile gelen erkek olgulardan kaynaklandığı görüldü. Evre 1, 2 ve 3 olgularının cinsiyete göre karşılaştırılmasında anlamlı farklılık saptanmadı $(\mathrm{p}>0.05)$.

Anevrizma ameliyatları için bir olguda suboksipital diğer olguların tümüne klasik pterional veya orbitozigomatik frontotemporal kraniotomi yapıldı. Anevrizma boynunun en iyi görüldüğü aç1, üç boyutlu BT angiografi görüntülerinde cerrah tarafindan belirlendikten sonra olguların baş pozisyonu verildi. Kanamış anevrizmaların kanama zamanı ile operasyon arasinda ortalama $2.53 \pm 2.16$
(0-11) gün vardı. Olgular kliniğimize kabul edilir edilmez tetkikleri yapıldıktan sonra başvuru evresine bakılmaksızın ameliyata alınmaya çalışıldı. Ancak pupilleri genişlemiş, 1şık reaksiyonu ve ağrllı uyarana yanitı olmayan olgulara medikal tedavi uygulandi.

Ameliyat edilen olguların ortalama yaşı $53.5 \pm 12.2$ (12-79), K/E oranı $160 / 110$ ve cinsiyete göre 
ortalama yaş dağı̆lımı; $55.1 \pm 14.6(12-79) / 51.3 \pm 11.15$ (18-77) idi (Tablo 2). Olguların 270'inde toplam 313 anevrizma tespit edildi ve toplam 311 anevrizma cerrahi olarak kliplendi (Șekil 1,2,3,4 ve 5). Anevrizmaların \%96.2'si anterior, \%3.8'i posterior sirkülasyon yerleşiminde idi.

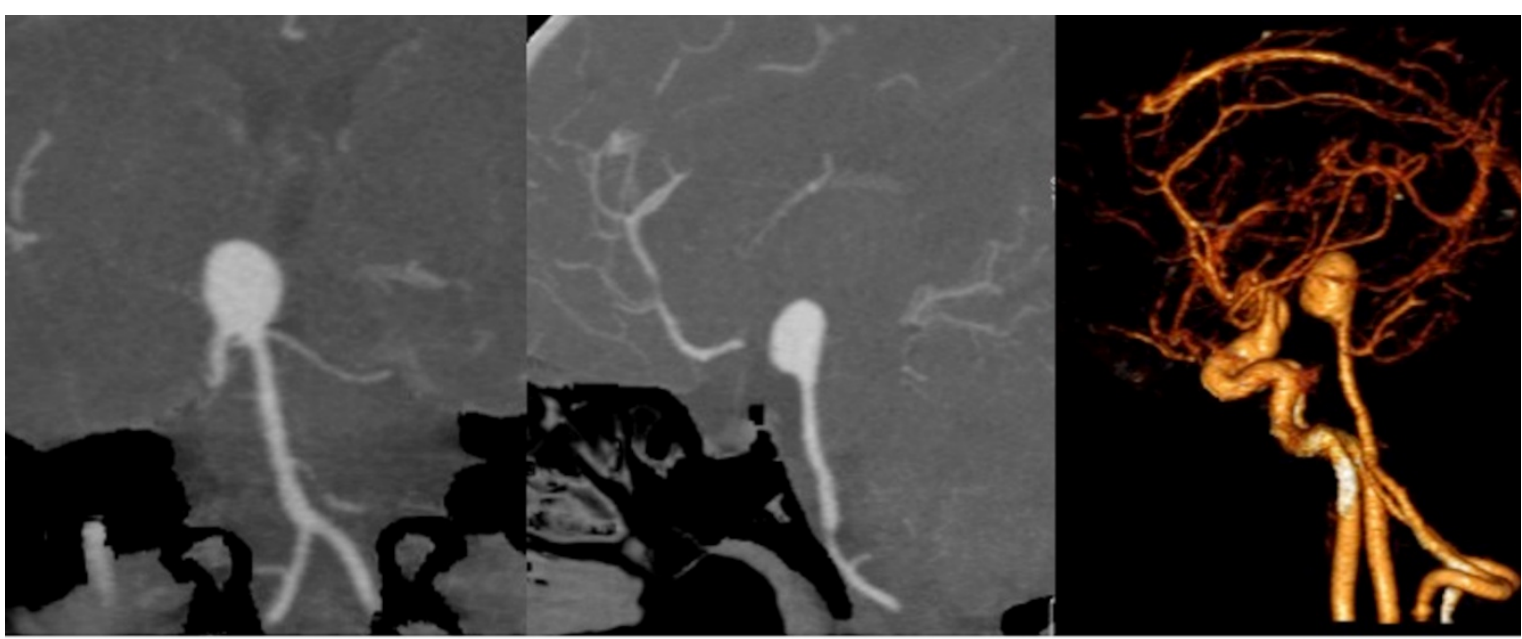

Resim 1. Subaraknoid kanama ile gelen 46 yaşında erkek olgunun ameliyat öncesi BT angiografi görüntüleri. Basiler tepede yerleșimli geniș boyunlu anevrizmatik genișleme mevcut.

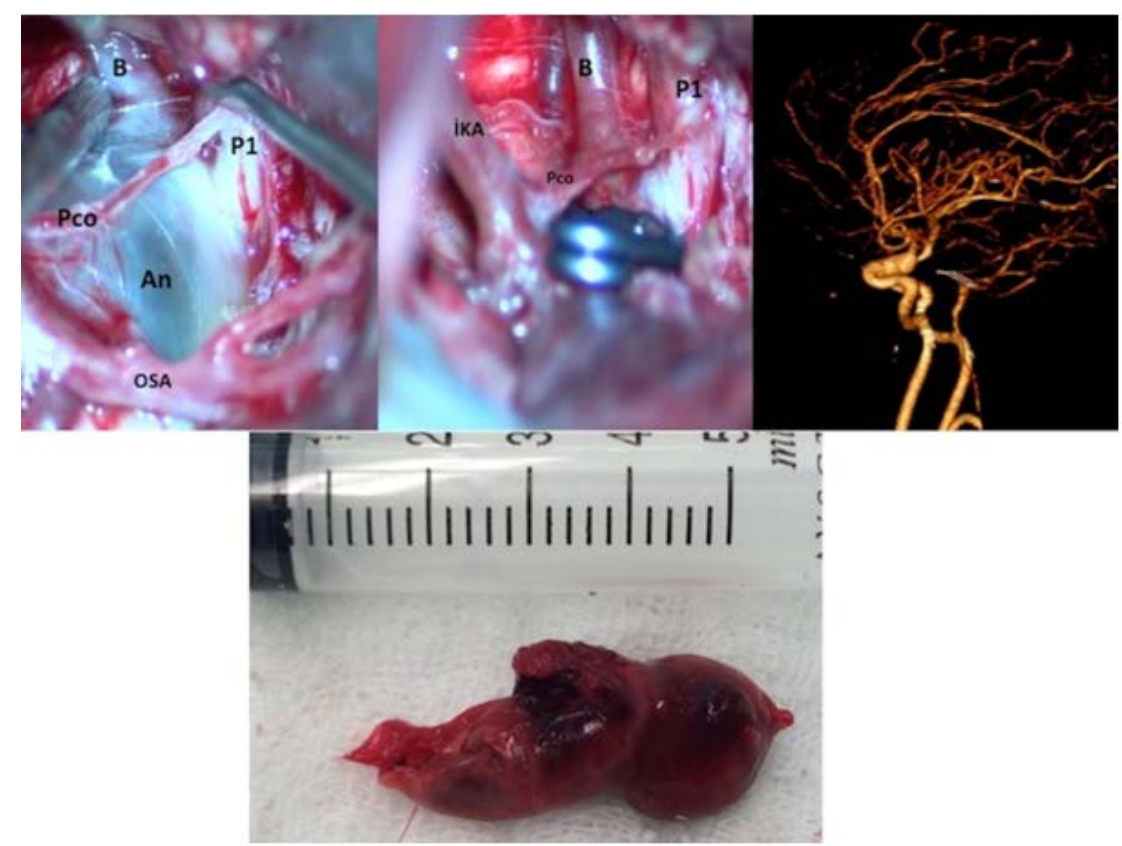

Resim 2. Basiler tepe yerleşimli olgunun ameliyat sırasındaki görünümü ve ameliyat sonrası kontrol BT angiografisi.

Sağ orbitozigomatik kraniotomi ile önce ekstradural anterior klinoidektomi yapıldı sonra intradural posterior klinod drillenerek anevrizmaya ulaşıldı. Anevrizmanın 3.ventrikül tabanına kadar uzanan, posterior klinoidi destrukte eden, İKA'yı öne itecek kadar sisterna işgali oluşturan ve postKomA’i germiş ve inceltmiş, yarıdan fazla bölümü tromboze olmuş dev anevrizma olduğu görüldü. Disseksiyon ile anevrizma boynuna ulaşlabildi, perforan arter ve posterior komminikan arter korunarak genis boyunlu anevrizma kliplendi ve eksize edildi.

Pco:Posterior komminikan arter, An:Anevrizma, B:Basiler arter, P1:Posterior serebral arter P1 segmenti, İKA:İnternal karotid arter, OSA:Orta serebral arter 


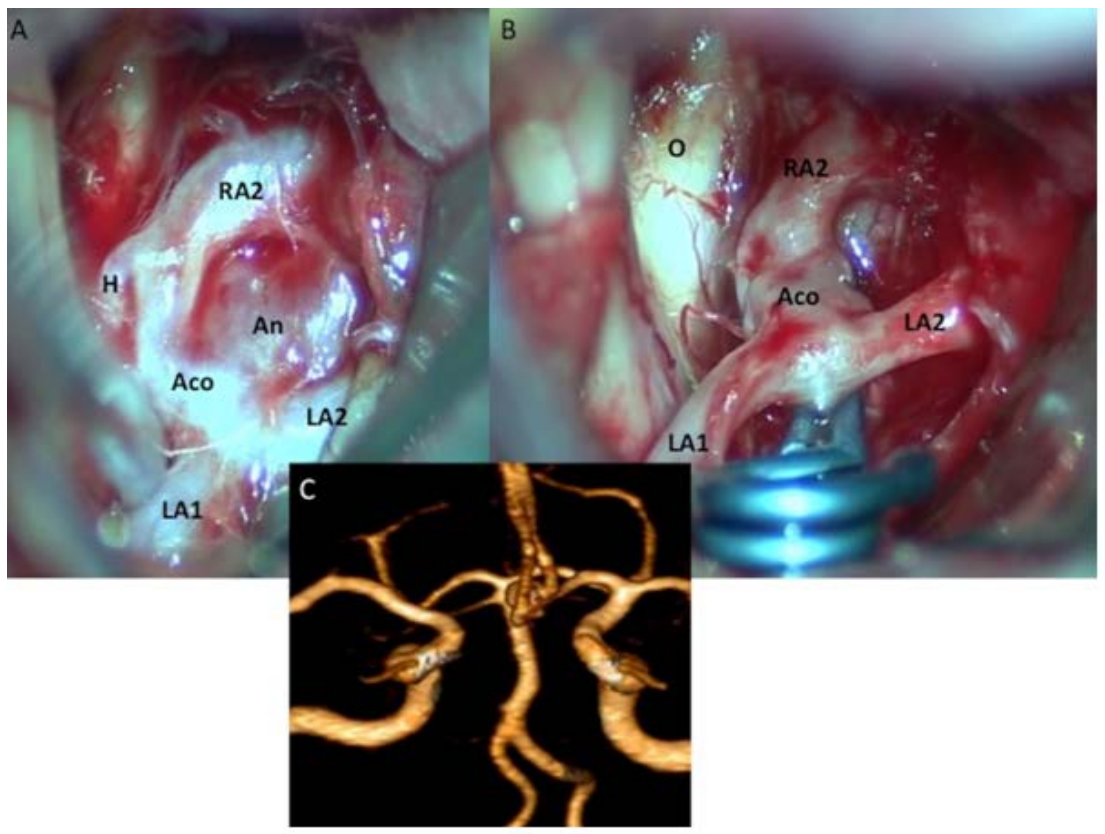

Resim 3. Să̆ anterior serebral arterin hipoplazik olduğu ve anterior-süperior uzanımlı bilobule anterior komminikan arter anevrizma olgusunun ameliyat öncesi BT angiografi (C) ve ameliyat sirasında klipleme öncesi (A) ve sonrası (B) görünümü.

LA1: Sol anterior serebral arter A1 segmenti, Aco:Anterior komminikan arter, An:Anevrizma, LA2: Sol anterior serebral A2 segmenti, RA2:Sağ anterior serebral arter A2 segmenti

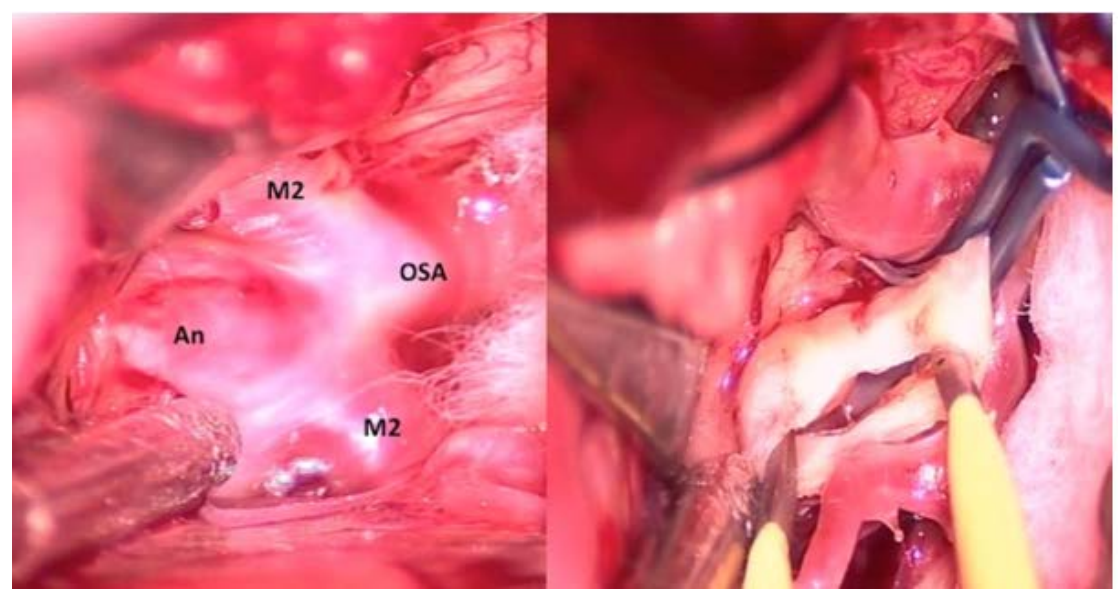

Resim 4. Sağ orta serebral arter anevrizmasının klip öncesi ve bipolar ile anevrizmanın şekillendirilip klipleme sonrasındaki görünümü.

An:Anevrizma, OSA:Orta serebral arter anevrizmas1, M2:Orta serebral arter M2 segmenti 


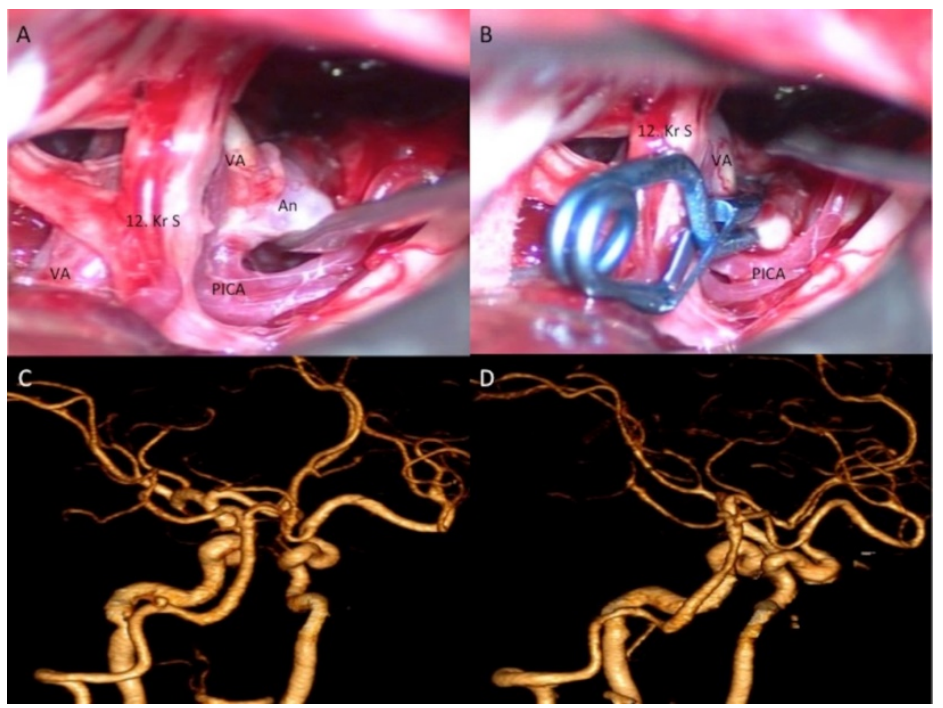

Resim 5. Sağ vertebral arterin gözlenemediği, olguda sol PICA çıkışında kanamış anevrizmatik genişlemenin ameliyat sırasında klip öncesi (A) ve sonrası (B) görünümü ile BT angiografi ile ameliyat öncesi (C) ve sonrası (D) görünüm.

VA:Vertebral arter, An:Anevrizma, PICA:Posterior inferior serebeller arter, Kr S 12:Kranial sinir 12

Tablo 3. Tek anevrizmalı olguların anevrizma bölgesel dağılımı

\begin{tabular}{|c|c|c|c|c|c|c|c|}
\hline & $\begin{array}{l}\text { Kanamamış } \\
\text { Anevrizma }\end{array}$ & $\begin{array}{l}\text { Kanamış } \\
(\mathrm{SAK}) \\
\text { Anevrizma }\end{array}$ & Ölüm & $\begin{array}{l}\text { İntraserebral } \\
\text { Hematomlu } \\
\text { Fisher grade } \\
\text { IV } \\
\text { anevrizma }\end{array}$ & Ölüm & $\begin{array}{l}\text { TOPLAM } \\
(\mathrm{n}: 232)\end{array}$ & $\begin{array}{l}\text { TOPLAM } \\
\text { Ölüm }\end{array}$ \\
\hline AntKomA & $5(\% 7.2)$ & $54(\% 78.3)$ & $4(\% 5.8)$ & $10(\% 14.5)$ & $6(\% 60)$ & $69(\% 29.7)$ & $10(\% 14.5)$ \\
\hline $\begin{array}{l}\text { İKA- } \\
\text { PostKomA }\end{array}$ & $7(\% 11.9)$ & $50(\% 84.7)$ & $1(\% 1.7)$ & $2(\% 3.4)$ & $1(\% 50)$ & $\begin{array}{l}59 \\
(\% 25.4)\end{array}$ & $2(\% 3.4)$ \\
\hline $\begin{array}{l}\text { Orta Serebal } \\
\text { Arter }\end{array}$ & $4(\% 7.1)$ & $38(\% 67.9)$ & $4(\% 7.1)$ & $14(\% 25)$ & $\begin{array}{l}10 \\
(\% 71.4)\end{array}$ & $56(\% 24.1)$ & $14(\% 17.6)$ \\
\hline$\dot{\mathrm{I} K A}$ & $1(\% 10)$ & $9(\% 90)$ & & & & $10(\% 4.3)$ & \\
\hline Basiler Arter & $1(\% 10)$ & $9(\% 90)$ & $1(\% 10)$ & & & $10(\% 4.3)$ & $1(\% 10)$ \\
\hline $\begin{array}{l}\text { İKA-Ant } \\
\text { Koroidal } \\
\text { Arter }\end{array}$ & & $7(\% 100)$ & & & & $7(\% 3.1)$ & \\
\hline $\begin{array}{l}\text { İKA A1-M1 } \\
\text { Bifurkasyon }\end{array}$ & $1(\% 12.5)$ & $6(\% 75)$ & & $1(\% 12.5)$ & & $8(\% 3.5)$ & \\
\hline DASA & & $2(\% 66.6)$ & $1(\% 33.3)$ & $1(\% 33.3)$ & & $3(\% 1.3)$ & $1(\% 33.3)$ \\
\hline $\begin{array}{l}\text { Oftalmik } \\
\text { Arter }\end{array}$ & $1(\% 16.7)$ & $5(\% 83.3)$ & & & & $6(\% 2.6)$ & \\
\hline $\begin{array}{l}\text { Blister } \\
\text { Anevrizma }\end{array}$ & & $3(\% 100)$ & $1(\% 33.3)$ & & & $3(\% 1.3)$ & $1(\% 33.3)$ \\
\hline PİCA & & $1(\% 100)$ & & & & $1(\% 0.4)$ & \\
\hline TOPLAM & $20(\% 8.6)$ & $184(\% 79.3)$ & $12(\% 6.5)$ & $28(\% 12.1)$ & $17 \% 60)$ & $232(\% 100)$ & $29(\% 12.5)$ \\
\hline
\end{tabular}

Tek anevrizmalı olguların anevrizma bölgesel dağılımında \%96.2 anterior sirkülasyon, $\% 3.8$ 'i posterior sirkülasyon yerleșimliydi. Anevrizma lokalizasyonlarına göre en fazla AntKomA kompleksinde geliştiği saptandı. Genel ölüm oranı \%12.5 idi. Kanamamıs anevrizmalarda ölüm yaşanmazken SAK ile gelen olgularda \%6.5, intraserebral hematomun eşlik ettiği Fisher grade IV ile başvuran olgularda \%60.7 oranında ölüm olustu. İstatistiksel olarak da hematom ile prognoz arasında anlamlı iliski saptandı $(\mathrm{p}<0.001)$.

AntKomA: Anterior komminikan arter, İKA: İnternal karotid arter, DASA:Distal anterior serebral arter, PİCA:Posterior inferior serebeller arter 
Tek anevrizmalı olgu sayımız $232(\% 85.9)$ idi. Bu olgular arasında $20 \mathrm{olgu}$ (\%8.6) kanamamıș, 184’ü (\%79.3) SAK veya intraserebral hematoma (Fisher grade IV) neden olmuştu. Anevrizmaların anatomik lokalizasyonuna göre dağılımında en çok anterior komünikan arter (AntKomA) (\%29.7), posterior komünikan arter (PostKomA) (\%25.4), orta serebral arter (OSA) (\%24.1) yerleşimliydi. Tek anevrizmalı olgularımızda toplam ölüm oranımız $\% 12.5$ saptandı. Kanamamış anevrizmalarda ölüm yaşanmadi. Sadece SAK ile başvuran olgularda ölüm oran $\% 6.5$ iken intraserebral hematomun eşlik ettiği Fisher grade IV olgularda \%60.7 saptand. İstatistiksel olarak intraserebral hematom varlığ1 ile prognoz arasında güçlü ilişki saptand $1 \quad(r=0.66$, $\mathrm{p}<0.001)$ (Tablo 3).
Toplam 38 olguda (\%14.1) çoklu anevrizma saptandi. Toplam anevrizma sayıs 81 idi ve sıklikla OSA/AntKom (6 olgu), OSA/OSA (5 olgu), AntKom/A1-A2 bileşke (5 olgu) yerleşiminde idi. Aynı taraftan ulaşılabilen anevrizmalar tek seansta kliplendi. Ancak karşı taraf yerleşimli kanamamış anevrizmalar ayrı seansta ameliyat edildi. 38 olguda saptanan 81 anevrizmanin 79'u kliplendi. 2 olgu ilk cerrahi sonrası kaybedildiği için karşı taraf OSA anevrizmaları kliplenemedi (Tablo 4). Çoklu anevrizma olgularında vazospazma bağlı gelişen ilerleyici iskemik hasar nedeni ile \%26.3 oranında ölüm yaşandı. Çoklu anevrizma ile tek anevrizmalar karşılaştırıldığında çoklu anevrizmanın ölüm oranını etkileyen faktör olduğu saptandı $(\mathrm{p}<0.05)$.

Tablo 4. İntrakranial çoklu anevrizma olgularının dağılımı

\begin{tabular}{|l|c|c|c|}
\hline Çoklu Anevrizma lokalizasyonları & Hasta Sayısı & Anevrizma Sayıs1 & $\begin{array}{c}\text { Opere edilen } \\
\text { anevrizma sayıs1 }\end{array}$ \\
\hline OSA/AntKomA & $6(2)$ & 12 & 12 \\
\hline AntKomA/A1-2 Bileşke & $5(2)$ & 10 & 10 \\
\hline OSA/OSA & 5 & 10 & 10 \\
\hline PostKomA/PostKomA & $4(1)$ & 8 & 8 \\
\hline OSA/PostKomA & $4(1)$ & 8 & 6 \\
\hline OSA/Distal OSA & $3(1)$ & 6 & 6 \\
\hline AntKomA/PostKomA & 3 & 6 & 4 \\
\hline IKA A1-M1 Bifurkasyon/PostKomA & 2 & 4 & 2 \\
\hline IKA A1-M1 Bifurkasyon /Basiler arter & $1(1)$ & 2 & 5 \\
\hline OSA/OSA/PostKomA & $2(1)$ & 6 & 8 \\
\hline OSA/OSA/AntKomA & $3(1)$ & 9 & 79 \\
\hline Toplam & $38(10)$ & 81 & 79 \\
\hline
\end{tabular}

Parantez içindeki rakamlar ölüm ile sonuçlanan olgu sayısını göstermektedir. Bu olgularda, vazospazma bağlı gelişen ilerleyici iskemik hasarlar nedeni ile \%26.3 oranında ölüm oranı saptandı. Karşı taraf yerleşimli anevrizmalar ayrı seansta ameliyat edildi. 2 olgu ilk ameliyat sonrası kaybedildiği için toplam 81 anevrizmanın 79'u ameliyat edildi. Bu olgularda üçer anevrizma vardı.

Olguların başvuru H\&H evre ile cinsiyet arasında anlamlı derecede farklilik vard1 $\left(X^{2}=9.8181, \mathrm{p}<0.05\right)$. $\mathrm{Bu}$ farklılı̆̆ın evre 4 ve 5 ile gelen erkek olgulardan kaynaklandığ1 saptandı. Evre 1, 2 ve 3 olgularının cinsiyete göre karşılaştırılmasında anlamlı farklılık saptanmadi ( $\left.X^{2}=1.397, \mathrm{p}>0.05\right)$ (Tablo 2 ve 5). Başvuru H\&H evre ile vazospazm gelişmesi arasinda anlamlı ilişki olduğu saptandı $\left(X^{2}=9.383, \mathrm{p}<0.05\right)$. Korelasyon testlerinde $\mathrm{H} \& \mathrm{H}$ evre ile Fisher evre $(\mathrm{r}=0.69, \mathrm{p}<0.001), \quad \mathrm{H} \& \mathrm{H}$ ile GGOS $(\mathrm{r}=0.60$, $\mathrm{p}<0.001)$ ve Fisher evre ile GGOS $(\mathrm{r}=0.50$, $\mathrm{p}<0.001)$ arasinda anlamlı korelasyonlar saptand.

Ameliyat edilen 270 anevrizma olgularında 39 (\%14.4) ölüm, 58 (\%21.5) sakatlık yaşandı (GGOS skoru 2-3-4-5-6 olan olgular, sakatlik olarak değerlendirildi). Kaybedilen olguların 22 tanesi (\%56.4) H\&H evre 4-5 olgular idi (Tablo 5 ve 6). Bu olguların ameliyat sonrası takiplerinde nörolojik düzelme olmadı, iskemik hasar, uzayan yoğun bakım tedavisi sırasında oluşan enfeksiyon ve akciğer sorunları nedeni ile kaybedildi. Olgularımıza klinik bulgular ile vazospazm teşhisi konuldu. Klinik bulgu, BT ve/veya diffüzyon MRI ile vazospazma bağlı iskemi saptanan 53 (\%19.6) olgudan 18'i (\%33.9) HHH, nimodipin tedavisine rağmen ilerleyici iskemik hasarlar nedeni ile kaybedildi. 270 olguda vazospazma bağlı ölüm oranımız \%6.7 idi. Kronik böbrek yetmezliği olan ve dializ ile takip edilen 2 olgu ameliyat sonrası klinik sorunu olmamasına rağmen dializ sonrası şuur bozukluğu ve 
ilerleyici iskemik hasarlar sonucunda, 1 olgumuz duodenal ülser perforasyonu ve subhepatik abse, 1 olgumuz da cerrahi komplikasyon nedeniyle kaybedildi. (Tablo 6).

Toplam 313 anevrizma cerrahisi sirasinda ameliyat sirasinda toplam $87(\% 27.8)$ anevrizma kanamas1 oldu. Disseksiyon sirasinda $72(\% 23)$, prematur 4 (\%1.3) ve klipleme sirasinda 11 (\%3.5) anevrizmada kanama oldu. $\mathrm{Bu}$ olguların tümünde ve anevrizma boyun bölgesinde yapışıklık olan anevrizmalarda geçici klip kullanıldı. Geçici klip uygulama öncesinde sodyum tiopental infüzyonu uygulandı. Olguların 52 tanesine ameliyat pozisyonu verilmeden lomber drenaj seti uygulandı ve dura açıldıktan sonra beyin omirilik sıvısı (BOS) drenaj1 yapıldı. Bu olguların hiçbirinde erken kanama olmadı. Ameliyat sonrası takipte toplam $38(\% 14.1)$ olguya hidrosefali kliniği nedeni ile ventriküloperitoneal shunt takıld. Postoperatif takipte $17(\% 6.3)$ olguda diabetes insipitis ve 11 (\%4.1) olguda serebral tuz kayb1 sendromu gelişti. Serebral tuz kaybı gelişen olgular semptomatik tedavi edildi, diabetes insipitis olgularından 4 tanesi vazopressin ile taburcu edildi. Opere edilen olgularin 11 (\%4.1)'inde operasyona bağlı komplikasyonlar oluştu. Bunlar serebellar uzak kanama, parankimal kontuzyon veya hematom, epidural ve subdural kanamalar idi. Ameliyat endikasyonu olan olgular opere edildi. Bir olgu kaybedildi, 7 olgunun GGOS sonucu negatif yönde etkilendi.

Tablo 5. Ameliyat edilemeyen veya angiografi normal olan SAK olguları ile anevrizma nedeni ile ameliyat edilen olgularının H\&H evrelemesine göre sakatlık ve ölüm oranlarının dağılımı.

\begin{tabular}{|l|c|c|c|c|c|c|c|c|c|}
\hline & \multicolumn{3}{|c|}{$\begin{array}{c}\text { Angiografi negatif veya } \\
\text { ameliyat edilmeyen olgular }\end{array}$} & \multicolumn{2}{c|}{ Opere edilen olgular } & \multicolumn{3}{c|}{ Toplam } \\
\hline & $\begin{array}{c}\text { Olgu } \\
\text { say1s1 }\end{array}$ & Sakatlik & Ölüm & $\begin{array}{c}\text { Olgu } \\
\text { sayls1 }\end{array}$ & Sakatlı & Ölüm & $\begin{array}{c}\text { Olgu } \\
\text { sayı1 }\end{array}$ & Sakatlık & Ölüm \\
\hline H\&H Evre 1 & $\begin{array}{c}28 \\
(\% 37.8)\end{array}$ & 0 & 0 & $\begin{array}{c}45 \\
(\% 16.7)\end{array}$ & 2 & 0 & $\begin{array}{c}73 \\
(\% 21.2)\end{array}$ & 2 & 0 \\
\hline H\&H Evre 2 & $\begin{array}{c}9 \\
(\% 12.2)\end{array}$ & 0 & 0 & $\begin{array}{c}78 \\
(\% 28.9)\end{array}$ & 11 & 4 & $\begin{array}{c}87 \\
(\% 25.3)\end{array}$ & 11 & 4 \\
\hline H\&H Evre 3 & $\begin{array}{c}8 \\
(\% 10.8)\end{array}$ & 2 & 1 & $\begin{array}{c}96 \\
(\% 35.5)\end{array}$ & 16 & 13 & $\begin{array}{c}104 \\
(\% 30.3)\end{array}$ & 18 & 14 \\
\hline H\&H Evre 4-5 & $\begin{array}{c}29 \\
(\% 39.2)\end{array}$ & 3 & 26 & $\begin{array}{c}51 \\
(\% 18.9)\end{array}$ & 29 & 22 & $\begin{array}{c}80 \\
(\% 23.2)\end{array}$ & 32 & 48 \\
\hline Toplam & $\begin{array}{c}74 \\
(\% 100)\end{array}$ & $\begin{array}{c}5 \\
(\% 6.8)\end{array}$ & $\begin{array}{c}27 \\
(\% 36.5)\end{array}$ & $\begin{array}{c}270 \\
(\% 100)\end{array}$ & $\begin{array}{c}58 \\
(\% 21.5)\end{array}$ & $\begin{array}{c}39 \\
(\% 14.4)\end{array}$ & $\begin{array}{c}344 \\
(\% 100)\end{array}$ & $\begin{array}{c}63 \\
(\% 18.3)\end{array}$ & $\begin{array}{c}66 \\
(\% 19.2)\end{array}$ \\
\hline
\end{tabular}

Toplam 344 SAK ve anevrizma olgu başvurusunda genel ölüm oranı \%19.2, H\&H evre 4-5 başvuru oranı \%23.3 idi. Anevrizma ameliyat yapılan olgular arasında ölüm oranı \%14.4 olarak saptandı. Ölüm ile sonuçlanan 39 olgunun $22(\% 56.4)$ H\&H evre 4-5 idi. İstatistiksel değerlendirmede ameliyat edilen anevrizma olgularında H\&H evre ile ölüm arasında anlamlı ilişki olduğu saptandı (p<0.001). (GGOS skoru 2-3-4-5-6 olan olgular, sakatlık olarak değerlendirildi)

Tablo 6: Ameliyat edilen 270 olgunun ölüm ve sakatlık oranları ile nedenleri.

\begin{tabular}{|l|c|c|c|}
\hline & Ölüm & Sakatlik & Toplam \\
\hline $\begin{array}{l}\text { İntraserebral hematom (Fisher } \\
\text { evre IV) }\end{array}$ & 17 & 11 & $28(\% 10.4)$ \\
\hline Vazospazm & 18 & 35 & $53(\% 19.6)$ \\
\hline Medikal tedavi komplikasyonu & 3 & & $3(\% 1.1)$ \\
\hline Ameliyat komplikasyonu & 1 & 7 & $8(\% 3)$ \\
\hline Hidrosefali & & $58(\% 21.5)$ & $97(\% 35.9)$ \\
\hline Toplam & $39(\% 14.4)$ & 58.9 & 97 \\
\hline
\end{tabular}

Intraserebral hematom ve vazospazm en fazla sakatlık ve ölüm neden oldu. Klinik ve radyolojik olarak vazospazm bulguları saptanan 53 olgunu 18’i (\%33.9) kaybedilmiştir. Olguların geliş nörolojik durumuna bakılmaksızın anevrizma cerrahisi yapılan 270 olguda genel olarak \%35.9 oranında sakatlık-ölüm gelişme riski oluştuğu saptandı. 


\section{TARTIŞMA}

İntrakranial anevrizmaların tedavisinde alternatif tedavi yöntemi geliştirilmesine rağmen cerrahi klipleme halen altin standart olan yerini korumaktadır. 1990 yılında Gugliemi tarafından geliştirilen endovasküler girişim ile anevrizma içinin koil ile doldurma tedavi yönteminin 1995 y1linda FDA onayı almasindan sonra yaygin bir şekilde kullanılmaya başlanmıştır. 2002 yılında yayınlanan International Subarachnoid Aneurysm Trial (ISAT) çalışmasından sonra intrakranial anevrizmaların endovasküler koil embolizasyon (EKE) sonuçlarının mikrocerrahiye eşit veya daha iyi olduğu ileri sürülmüștür ${ }^{12}$. Ancak toplam olguların küçük bir kısmının randomize edilmesi, mikrocerrahi veya EKE seçiminde EKE lehine randomizasyon yapılması, hangi hastaya EKE uygulanacağını gösteren bir guideline sağlamaması, çalışmaya katılan merkezlerin Avrupa, Kanada ve Avustralya'dan olması, cerrah ve endovasküler girişimcilerinin deneyimleri hakkında bilgi verilmemesi, olguların \%80'inin iyi klinik seviyesinde olmas1 ( $\mathrm{H} \& \mathrm{H}$ evre 1 veya 2), anevrizmaların \%93'ünün $\leq 10 \mathrm{~mm}$ ve \%97'sinin anterior sirkülasyonda olması bu çalışma için tartışılan konular olmuştur. Zaman içinde endovasküler teknik ve kullanılan malzemelerin (onyx, stent, akım değiştiriciler, balon yardımlı koil vb) gelişmesi ile özellikle yaşlı hastalar (75 yaş üstü), yüksek evre, ulaşımı güç rüptüre olmuş anevrizmalar, anevrizma konfigürasyonu (dom/boyun oranı $<0.5$, boyun kalınlığ $1<5 \mathrm{~mm}$ ), posterior sirkülasyon anevrizmaları, Plavix benzeri antiagregan kullanan kanamıs anevrizmalar da EKE ile anevrizmanın tedavisini ön plana çıkarmaktadır ${ }^{14,15}$. Son y1llarda ülkemizde yaygınlaşmasına rağmen EKE konusunda tecrübeli merkezler oldukça sınırlı sayıda kalmıştır. Çalıştığımız şehirde endovasküler girişim yapılmaması nedeni ile tüm hastalara bu girişim hakkında bilgi verildikten sonra cerrahi olarak tedavileri önerilmiş, kabul eden olgular ameliyat edilmiştir.

Anevrizmanın gerek cerrahi, gerekse de endovasküler yol ile tedavi edilebiliyor olmasına rağmen SAK'ın oluştuğu anda ki ani kafa içi basınç artışı ve serebral perfüzyon basıncinın düşmesi nedeni ile oluşan beyin hasarı, erken dönemde önemli sakatlık ve ölümlere neden olmaktadır.,16 SAK sonucu oluşan erken beyin hasarına bağl1 olarak olgularımız \%2.6 oranında kardiak arrest ve $\% 23.3$ oranında koma halinde başvurmuştur.
Tomografideki kanama miktarı ile sonuç arasında ki ilişki vazospazm gelişmesi açısından önemli bir faktör olduğu bilinmektedir ${ }^{17,18}$. Aynı zamanda başvurudaki şuur seviyesinin derecesi ve kanamanın miktarının da sonucu etkileyen güçlü bir faktör olduğu bildirilmiştir ${ }^{10,19}$. Ancak bu hastalarda da hedef, kanamaya neden olan anevrizmanin tekrar kanama riskini ortadan kaldırmak ve ikincil hasarların önüne geçebilmektir. Bu amaca yönelik olarak kanamış anevrizmaların tedavi zamanlaması da ayrı bir tartışma konusudur ${ }^{20}$. Tekrar kanamanın \%4'ünün ilk 24 saatte olması, üçüncü günden sonra oluşan vazospazm ile mücadele için uygulanan $\mathrm{HHH}$ tedavisinin tekrar anevrizma kanama riski olmadan yapilabilmesi, subaraknoid mesafede bulunan potansiyel vazospazmojenik ajanların cerrahi sırasında ortamdan uzaklaştırılması, ameliyata bağlı ölüm oranının daha yüksek olmasına rağmen genel ölüm oranının daha düşük olması nedenleri ile erken cerrahi savunulmaktadır 11,21,22. Öte taraftan SAK sonrası oluşan beyin ödemi nedeni ile ameliyat sırasında gereğinden fazla beyin ekartasyonuna bağlı komplikasyonlar, ameliyat sirasinda anevrizma kanamasının daha yüksek olması, intrakranial damarlara yapılan mekanik travmanin muhtemel vazospazm riski oluşturması nedenleri ile de erken cerrahiye karşı iddalar mevcuttur. Ancak iyi medikal ve nörolojik durumda olan olgular, bası etkisi olan intraserebral hematomun varlığ1, erken kanamanın ve/veya bilinen tekrar kanamaların olmasi, angiografi sirasinda anevrizmada pulsatil değişikliklerin olması (beating anevrizma bulgusu), tekrarlayan angiografilerde anevrizma boyutunun artmas1, özellikle posterior komünikan arter anevrizmalarında görülen ilerleyici kranial sinir paralizilerinde erken anevrizma cerrahisi için önemli faktörlerdir ${ }^{10,11,23,24}$. Olgularımız yoğun bakım ünitesine yatır1ldiktan sonra hemen ileri tetkikleri yapılarak ortalama 2.5 gün de ameliyata alınmıştır. Vazospazm ile mücadele konusunda önemli avantajlar sağlaması ve önlenebilir ölüm nedeni olan tekrar kanama riskini ortadan kaldırdığı için $\mathrm{H} \& \mathrm{H}$ evre 4-5 olsa bile erken cerrahi ile olgularımız ameliyat edilmiştir. Kanamanın doğrudan etkisine bağlı olarak H\&H evre 4 ve 5 olarak gelen toplam anevrizma olgularımızın oranı \%18.9 idi. Genel ölüm oranımızın önemli bir bölümünü bu hastalar oluşturmakta idi. Olgularımızın $\mathrm{H} \& \mathrm{H}$ evre ile vazospazm gelişimi ve GGOS karşılaştırılmasında literatür ile uyumlu ilişki saptand1 11,19,20,22.

Subaraknoid mesafede, vazospazmojenik kan ürünlerinin tetiklediği karışı mekanizmalar 
sonucunda SAK sonrasi vazospazm \%30-45 oranında ${ }^{17,25,26}$. Kanama sonrasi genellikle 3-14 gün arasında görülen vazospazm başarılı anevrizma cerrahisine rağmen fokal veya ilerleyici nörolojik defisit hatta ölüm ile sonuçlanabilmektedir ${ }^{17}, \quad 27$. Vazospazm ile $\mathrm{H} \& \mathrm{H}$ evre ve subaraknoid mesafedeki kan miktarı arasında bir ilişki olduğu bildirilmiştir ${ }^{6,18,28}$. Klinik vazospazm tedavisinde kalsiyum kanal ve endotelin reseptör blokörleri, $\mathrm{HHH}$ tedavisi, intraarteryel papaverin, mekanik arteryel dilatasyon ve angioplasti yöntemleri kullanılmasına rağmen ne yazık ki yüzde yüz başarılı bir tedavi protokolü halen bulunmamaktadır 22,29-31 . Vazospazm ile mücadele konusunda perkütan transluminal angioplasti ve intraarteriyel vazodilatatör enjeksiyonu gibi girişimsel yöntemler de kullanılmaktadır. Ancak büyük damarların yanında mikrokapiller düzeyde gerçekleşen ve dinamik süreç olan vazospazm için standartlaşan tedavi haline gelemediği gibi uzun dönem sonuçları konusunda belirsizlik ve önemli komplikasyon riskleri olduğu da bildirilmiștir ${ }^{32}$. Olgularımızda vazospazm gelişme riski yüksek olanlara $\mathrm{HHH}$ tedavisi uygulanmıştır ve \%19.6 oranında vazospazm kliniği saptanmıştır. Başağrısı, fokal veya ilerleyici nörolojik defisit gelişen, laboratuvar ve radyolojik olarak vazospazm düşünülen olgular yoğun bakım ünitesinde sedasyon, analjezi, $\mathrm{HHH}$ tedavisi ve gerektiğinde uyutularak respiratöre bağlanarak takip edildi. Vazospazm gelişen hastalarımızın \%33.9'ü kaybedildi. Ameliyat sonrası dönemde olgularımız, sadece klinik ve radyolojik olarak takip edildiği için gerçek vazospazm oranı belirlenemediği için literatüre göre düşük oranda vazospazm geliştiği düșünülmüștür. Öte taraftan erken cerrahi ve sonrasında $\mathrm{HHH}$ tedavisinin etkin uygulanmasının vazospazm oranımızın düşük olmasına katkısı olduğunu düşünmekteyiz.

İntrakranial çoklu anevrizmaya \%34 oranında rastlanıldığ1, prognozun $\% 26$ oranında kötü sonuçlandığı, geç iskemik nörolojik defisit gelişiminin tek anevrizmalı SAK olgularına göre daha fazla oluştuğu bildirilmiştir ${ }^{33}$. Çoklu anevrizmalı olgularımızda ölüm oranımız tekli anevrizma olgularına göre anlamlı derecede fazlaydı. $\mathrm{Bu}$ hastalarda hangi anevizmanın kanadığını belirlemek önemlidir. Bilgisayarlı tomografi veya MRI tetkiklerinde çevresinde yoğun kanaması olan, angiografide fokal vazospazm alanına yakın ve düzensiz şekilli anevrizma muhtemel kanamış olandır. Eğer bu bulguların hiç biri yoksa en geniş anevrizmadan șüphelenilmelidir 34,35 . Çoklu anevrizma olgularımızın tümünde kanamış anevrizma vard1 ve kanama yoğunluğu ile kanamış olanı kolaylıkla saptand1. Bu olgularda genel prensip olarak öncelikle kanamış anevrizma kliplendikten sonra kanamamış anevrizmaya müdahale edilmiștir. Ancak klibin disseksiyonu zorlaştırabileceği ve görüş alanını daraltacağı durumlarda kanamıș anevrizmanın proksimal kontrolu için gerekli disseksiyon ve hazırlıklar yapıldıktan sonra tersine uygulamalarımızda olmuştur.

Beyin ekartasyonundan kaçınmak için kaideye doğru fazladan kemik alınmas1 veya BOS drenaj1 uygulanabilmektedir. Gereğinden fazla kemik alınması kozmetik sorunlara neden olabildiğinden hiperventilasyon, mannitol ve diüretik kullanımı ile beyin relaksasyonu sağlanmaya çalışılsa da BOS drenaj1 bu hedef için en etkili yöntemdir ${ }^{36}$. Sisterna disseksiyonu ile BOS aspire edilmesi, cerrahi sırasında uygulanabilmekte ancak yaygin kanama ve ödem nedeni ile bazen güçlükle sisternalara ulaşılabilmekte ve ekartasyona ihtiyaç duyulmaktadır. $\mathrm{Bu}$ durumlarda ventrikülostomi veya lomber drenaj seti ile BOS drenaj1 daha etkin bir yöntemdir. $\mathrm{Bu}$ yöntemler ile BOS drenajina ameliyat sonrası da devam edilebildiğinden vazospazmojenik ajanların subaraknoid mesafeden temizlenmesi ile vazospazm gelişme riskini azalttığı gibi kafa içi basınç ve serebral perfüzyon basınç üzerine olumlu etki oluşturur $^{36}$. Kanamış ve kliplenmemiş anevrizmalı hastalarda lomber BOS drenajinin korkulan en önemli komplikasyonu tekrar kanama riskinin arttırmasidır ${ }^{37}$. Yaygin SAK'1 ve ödem nedeni ile disseksiyon problemi yaşayacağımızı düşündüğümüz olgularımıza lomber drenaj seti takıldı. Tekrar kanama riskini azaltmak için nihai cerrahi pozisyon verilmeden lateral pozisyonda lomber drenaj seti yerleştirildi ve dura açıldıktan sonra anestezi tarafindan kontrollü BOS drenajı yapıldı. Kan ve kan ürünlerinin subaraknoid mesafeden uzaklaștırılması ve kafa içi basıncın düşürülmesine katkıda bulunması nedeni ile bu olguların BOS drenajina ameliyat sonrası en fazla 1 hafta kadar devam edildi.

Ameliyat sırasında, anevrizma rüptürü cerrahi sırasında $\% 40$ oranında olabilen bir komplikasyondur ${ }^{38}$. Erken cerrahide daha yüksek oranda olduğu bildirilmişse de erken ve geç cerrahi arasında bir fark olmadığ1 da bildirilmiştir ${ }^{9,38}$. Bu komplikasyon dura açılmadan veya anevrizmaya ulaşılmadan oluşması durumunda sakatlık ve ölüm üzerine doğrudan etkilidir ${ }^{38}$. Anevrizma cerrahisinde anevrizma rüptürü üç aşamanın birinde olmaktadır ${ }^{39}$. 
Anevrizma disseksiyon öncesi aşamasındaki erken rüptür nadirdir ancak beyinde ani şişme ve kortikal yırtılmalara sebep olacağından genellikle kötü prognoza neden olmaktadır. Kemiğin drillenmesi sırasında titreşimin etkisi, dura açıldığında kafa içi basıncın düşmesi ile anevrizma içi basıncın aniden yükselmesi, ağrıya yanıt olarak katekolamin deşarjı ile oluşan hipertansiyon bu aşamadaki erken kanama nedenleri olarak sayılabilir. Bu aşamadaki anevrizma kanama oranımız \%1.1 idi. Anevrizma disseksiyonu sırasında olan rüptür; anevrizma ameliyatı sırasında en fazla bu aşamada anevrizma kanaması oluşmaktadır. Künt disseksiyonun oluşturduğu yırtılmalar genellikle anevrizma boynu veya yakınındaki bölgelerde olabilmektedir. Bu durumda geçici klip ile kanama kontrolü sağlandıktan sonra anevrizma tamamen disseke edildikten sonra klipleme gerçekleştirilmelidir. Serimizde \%20.5 oranında bu aşamada kanama olmuştur. Klipleme aşamasındaki kanama; anevrizmanın yeterli derecede disseke edilmeden özellikle bilobüle anevrizmaların kliplenmesi sırasında, görülmeyen anevrizma bölümünün klip ucunun delmesi ile oluşmaktadır. Bu durumda klip kapatıldığında yırtı̆̆ın büyümesi ile daha şiddetli kanama oluşur. Beklenmedik aşırı kanamanın oluştuğu bu kanama şeklinde geçici klip kontrolünde klibin çıarılması ve anevrizmanın tamamen disseke edilmesi gerekmektedir. $\mathrm{Bu}$ aşamada \%4.1 oranında anevrizma kanamamız olmuştur. $\mathrm{Bu}$ komplikasyondan kaçınmak için anevrizma ve boyun çevresinin tamamen disseke edilmesi gerekir. $\mathrm{Bu}$ aşamadaki erken kanamanın önemli bir diğer nedeni de yetersiz klip çeşitliliği ve bunun sonucunda uygun olmayan klip ile anevrizma boynunun kliplenmeye çalışılmasıdır. Proksimal kontrolün sağlanabileceği disseksiyon ve hazırlıklar yapıldıktan sonra anevrizma disseksiyonu sırasinda kanamanın olması endişe verici bir durum değildir. Hatta geçici klip eşliğinde anevrizmanın kanaması ve aspiratörün ucu ile kanama odağının kapatılması anevrizma domunun küçülmesini sağlayacağından anevrizma disseksiyonunu daha da kolaylaştırabilmekte, özellikle geniş boyunlu anevrizmaların boynunun bipolar ile şekillendirilmesi ve kliplenmesi daha kolay olmaktadır.

Sonuç olarak; kanamış intrakranial anevrizmalar önemli sakatlık ve ölüm nedenidir. Özellikle çoklu anevrizmalar, H\&H evre 4-5 ve intraserebral hematom, sonucu etkileyen en önemli faktörlerdir. Tekrar kanama riski ve ameliyat sonrası vazospazm ile güvenli mücadele etmeye olanak sağlaması nedeni ile erken cerrahinin uygun olduğunu düşünmekteyiz.

\section{KAYNAKLAR}

1. Rinkel GJ, Djibuti M, Algra A, Van Gijn J. Prevalence and risk of rupture of intracranial aneurysms a systematic review. Stroke. 1998;29:2516.

2. Inagawa $\mathrm{T}$, Kamiya $\mathrm{K}$, Ogasawara $\mathrm{H}$, Yano $\mathrm{T}$. Rebleeding of ruptured intracranial aneurysms in the acute stage. Surg Neurol. 1987;28:93-9.

3. Broderick JP, Brott TG, Duldner JE, Tomsick T, Leach A. Initial and recurrent bleeding are the major causes of death following subarachnoid hemorrhage. Stroke. 1994;25:1342-7.

4. Drake C. Progress in cerebrovascular disease. Management of cerebral aneurysm. Stroke. 1981;12:273-83.

5. Hop JW, Rinkel GJ, Algra A, van Gijn J. Case-fatality rates and functional outcome after subarachnoid hemorrhage a systematic review. Stroke. 1997;28:660-4.

6. Fisher C, Kistler J, Davis J. Relation of cerebral vasospasm to subarachnoid hemorrhage visualized by computerized tomographic scanning. Neurosurgery. 1980;6:1-9

7. Hunt WE, Hess RM. Surgical risk as related to time of intervention in the repair of intracranial aneurysms. Journal of neurosurgery. 1968;28:14-20.

8. Symon L. Perspectives in aneurysm surgery. Acta Neurochir. 1982;63:5-13.

9. Kassell NF, Boarini DJ, Adams Jr HP, et al. Overall management of ruptured aneurysm: comparison of early and late operation. Neurosurgery. 1981;9:120-8.

10. Kassell NF, Torner JC, Haley Jr EC, Jane JA, Adams HP, Kongable GL. The International Cooperative Studyon the Timing of Aneurysm Surgery: Part 1: overall management results. J Neurosurg. 1990;73:18-36.

11. Kassell NF, Torner JC, Jane JA, Haley Jr EC, Adams HP. The international cooperative study on the timing of aneurysm surgery: Part 2: surgical results. J Neurosurg. 1990;73:37-47.

12. Molyneux A, Group ISATC. International Subarachnoid Aneurysm Trial (ISAT) of neurosurgical clipping versus endovascular coiling in 2143 patients with ruptured intracranial aneurysms: a randomised trial. Lancet. 2002;360:1267-74.

13. Wilson JL, Pettigrew LE, Teasdale GM. Structured interviews for the Glasgow Outcome Scale and the extended Glasgow Outcome Scale: guidelines for their use. J Neurotrauma. 1998;15:573-85.

14. Johnston SC, Higashida RT, Barrow DL, et al. Recommendations for the endovascular treatment of intracranial aneurysms a statement for healthcare professionals from the Committee on Cerebrovascular Imaging of the American Heart Association Council on Cardiovascular Radiology. Stroke. 2002;33:2536-44.

15. Debrun GM, Aletich VA, Kehrli P, Misra M, 
Ausman JI, Charbel F. Selection of cerebral aneurysms for treatment using Guglielmi detachable coils: the preliminary University of Illinois at Chicago experience. Neurosurgery. 1998;43:1281-95.

16. Cahill WJ, Calvert JH, Zhang JH. Mechanisms of early brain injury after subarachnoid hemorrhage. J Cereb Blood Flow Metab. 2006;26:1341-53.

17. Kassell N, Sasaki T, Colohan A, Nazar G. Cerebral vasospasm following aneurysmal subarachnoid hemorrhage. Stroke. 1985;16:562-72.

18. Lagares A, Jiménez-Roldán L, Gomez PA, et al. Prognostic value of the amount of bleeding after aneurysmal subarachnoid hemorrhage: a quantitative volumetric study. Neurosurgery. 2015;77:898-907.

19. Rosengart AJ, Schultheiss KE, Tolentino J, Macdonald RL. Prognostic factors for outcome in patients with aneurysmal subarachnoid hemorrhage. Stroke. 2007;38:2315-21.

20. de Gans K, Nieuwkamp DJ, Rinkel GJ, Algra A. Timing of aneurysm surgery in subarachnoid hemorrhage: a systematic review of the literature. Neurosurgery. 2002;50:336-42.

21. Milhorat TH, Krautheim M. Results of early and delayed operations for ruptured intracranial aneurysms in two series of 100 consecutive patients. Surg Neurol. 1986;26:123-8.

22. wad IA, Carter LP, Spetzler RF, Medina M, Williams F. Clinical vasospasm after subarachnoid hemorrhage: response to hypervolemic hemodilution and arterial hypertension. Stroke. 1987;18:365-72.

23. Malek AM, Halbach VV, Holmes S. Beating aneurysm sign: Angiographic evidence of ruptured aneurysm tamponade by intracranial hemorrhage: Case illustration. J Neurosurg. 1999;91:517-7.

24. Chyatte D, Fode NC, Sundt Jr TM. Early versus late intracranial aneurysm surgery in subarachnoid hemorrhage. J Neurosurg. 1988;69:326-31.

25. Weir B, Grace M, Hansen J, Rothberg C. Time course of vasospasm in man. J Neurosurg. 1978;48:173-8.

26. Solenski NJ, Haley Jr EC, Kassell NF, et al. Medical complications of aneurysmal subarachnoid hemorrhage: a report of the multicenter, cooperative aneurysm study. Participants of the Multicenter Cooperative Aneurysm Study. Crit Care Med. 1995;23:1007-17.

27. Ferguson S, Macdonald RL. Predictors of cerebral infarction in patins with aneurysmal subarachnoidal hemorrhage. Neurosurgery. 2007;60:658-67.
28. Kistler J, Crowell R, Davis K, et al. The relation of cembral vasospasrn to the extent and location of subarachnoid blood visualized by CT scan A prospective study. Neurology. 1983;33:424-424.

29. Wilkins RH. Attempts at prevention or treatment of intracranial arterial spasm: an update. Neurosurgery. 1986;18:808-25.

30. Allen GS, Ahn HS, Preziosi TJ, Battye R, Boone SC, Boone SC, Chou SN et al. Cerebral arterial spasm-a controlled trial of nimodipine in patients with subarachnoid hemorrhage. $N$ Engl J Med. 1983;308:619-24.

31. Connolly ES, Rabinstein AA, Carhuapoma JR, et al. Guidelines for the management of aneurysmal subarachnoid hemorrhage a guideline for healthcare professionals from the American heart association/American stroke association. Stroke. 2012;43:1711-37.

32. Athar MK, Levine JM. Treatment options for cerebral vasospasm in aneurysmal subarachnoid hemorrhage. Neurotherapeutics. 2012;9:37-43.

33. Rinne J, Hernesniemi J, Puranen M, Saari T. Multiple intracranial aneurysms in a defined population: prospective angiographic and clinical study. Neurosurgery. 1994;35:803-8.

34. Karttunen A, Jartti P, Ukkola V, Sajanti J, Haapea M. Value of the quantity and distribution of subarachnoid haemorrhage on CT in the localization of a ruptured cerebral aneurysm. Acta neurochirurgica. 2003;145:655-61.

35. Hackney DB, Lesnick JE, Zimmerman RA, Grossman RI, Goldberg HI, Bilaniuk LT. MR identification of bleeding site in subarachnoid hemorrhage with multiple intracranial aneurysms. J Comput Assist Tomogr. 1986;10:878-80.

36. Borkar SA. 183 Spinal cerebrospinal fluid drainage for prevention of vasospasm in aneurysmal subarachnoid haemorrhage: a prospective randomized controlled study. Neurosurgery. 2013;60:180-1.

37. Hasan D, Vermeulen M, Wijdicks E, Hijdra A, Van Gijn J. Management problems in acute hydrocephalus after subarachnoid hemorrhage. Stroke. 1989;20:747-53.

38. Schramm J, Cedzich CC. Outcome and management of intraoperative aneurysm rupture. Surg Neurol. 1993;40:26-30.

39. Batjer H, Samson D. Management of intraoperative aneurysm rupture. Clin Neurosurg. 1989;36:275-88. 